\title{
Correction to: Epicardial fat volume measured on nongated chest CT is a predictor of coronary artery disease
}

\author{
Yasunori Nagayama ${ }^{1} \cdot$ Naoki Nakamura $^{2} \cdot$ Ryo Itatani $^{2} \cdot$ Seitaro Oda ${ }^{1} \cdot$ Shinichiro Kusunoki ${ }^{2} \cdot$ Hideo Takahashi $^{2}$. \\ Takeshi Nakaura $^{1} \cdot$ Daisuke Utsunomiya $^{3} \cdot$ Yasuyuki Yamashita $^{1}$
}

Published online: 5 July 2019

(C) European Society of Radiology 2019

\section{Correction to: European Radiology (2019) 29:3638-3646} https://doi.org/10.1007/s00330-019-06079-x

The original version of this article, published on 11 March 2019, unfortunately contained a mistake. The following correction has therefore been made in the original: the presentation of Fig. 5 was incorrect. The corrected figure is given below.

Publisher's note Springer Nature remains neutral with regard to jurisdictional claims in published maps and institutional affiliations.

The online version of the original article can be found at https://doi.org/ 10.1007/s00330-019-06079-x

Yasunori Nagayama

y.nagayama1980@gmail.com

1 Department of Diagnostic Radiology, Graduate School of Medical Sciences, Kumamoto University, 1-1-1, Honjo, Chuo-ku, Kumamoto 860-8556, Japan

2 Department of Radiology, Minamata City General Hospital and Medical Center, 1-2-1, Tenjin-cho, Minamata 867-0041, Japan

3 Department of Diagnostic Radiology, Yokohama City University Hospital, 3-9 Fukuura, Kanazawa-ku, Yokohama 236-0004, Japan 
Fig. 5 The receiver operating characteristic curves for epicardial fat volume (EFV), as quantified on coronary $\mathrm{CT}$ angiography (CCTA, blue line, cutoff value $=$ $78.7 \mathrm{~cm}^{3}$, area under the curve $=$ $0.659)$ and nongated noncontrast CT (NCCT, red line, cutoff value $=101 \mathrm{~cm}^{3}$, area under the curve $=0.665$ ) to predict coronary artery disease

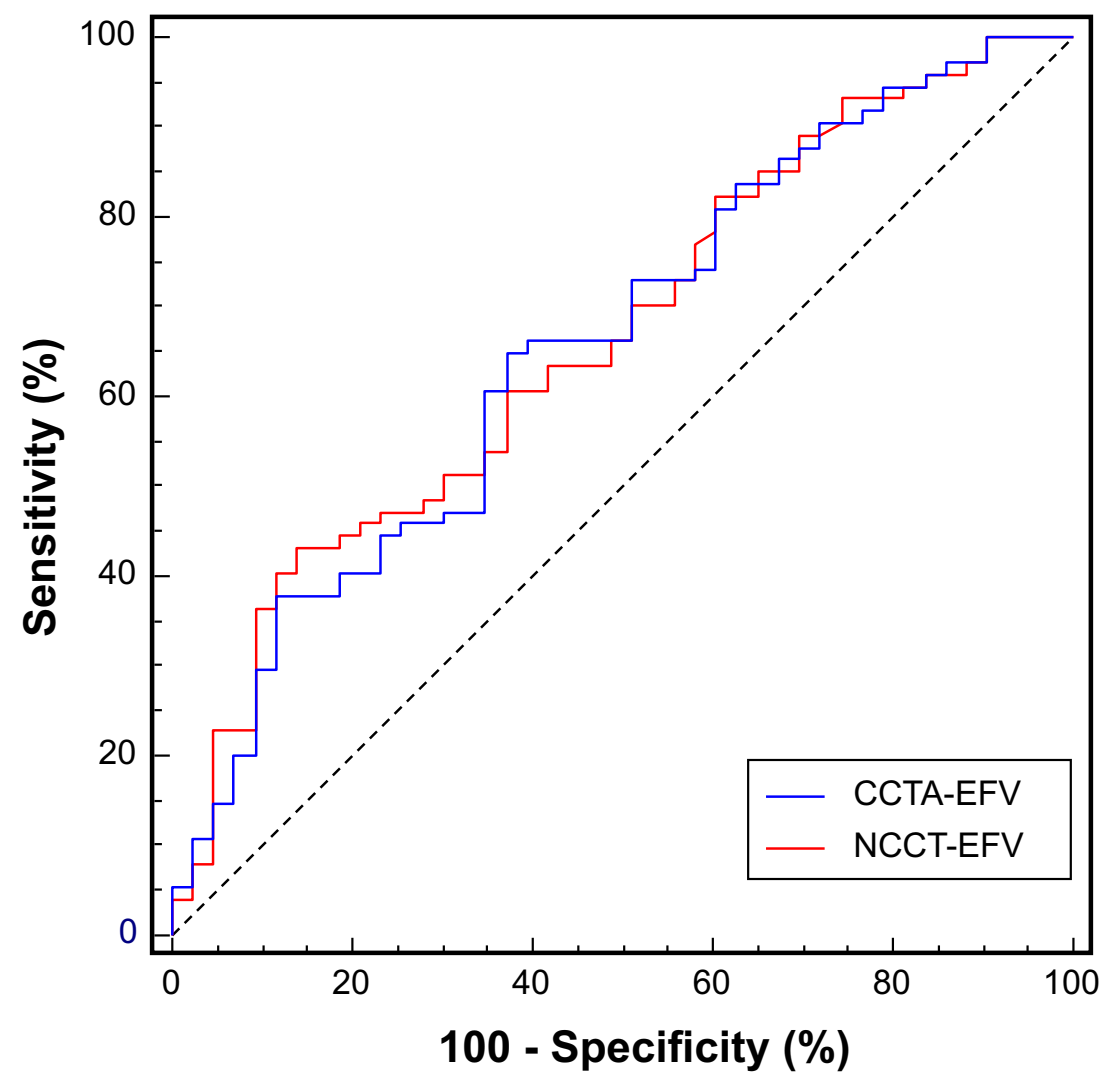

